\title{
METATARSALGIAS: DIAGNÓSTICO DIFERENCIAL POR MEIO DA RESSONÂNCIA MAGNÉTICA*
}

\author{
Maria Carolina Guimarães ${ }^{1}$, Claudia Kazue Yamaguchi ${ }^{2}$, André Yui Aihara ${ }^{3}$, \\ Luiz Guilherme Hartmann ${ }^{3}$, Jorge Pröglhöf ${ }^{1}$, Artur da Rocha Corrêa Fernandes ${ }^{4}$
}

Resumo Várias lesões podem causar metatarsalgia, cujas manifestações clínicas podem ser inespecíficas. As imagens de ressonância magnética, associadas a outros métodos de imagem e dados clínicos, freqüentemente podem contribuir na detecção dessas lesões e possibilitar que um diagnóstico relativamente preciso seja considerado. Nosso objetivo é descrever e ilustrar, por meio de imagens de ressonância magnética, as principais doenças que causam metatarsalgia.

Unitermos: Metatarsalgia; Doenças do pé; Artropatias; Imagem por ressonância magnética.

Abstract Metatarsalgias: differential diagnosis with magnetic resonance imaging.

Several lesions may cause metatarsalgia whose clinical manifestations may be non-specific. Magnetic resonance imaging associated with other imaging methods and clinical data frequently can contribute to detection of these lesions, allowing a reasonably precise diagnosis to be considered. Our purpose is to describe and illustrate, by means of magnetic resonance imaging, main diseases causing metatarsalgia.

Keywords: Metatarsalgia; Foot diseases; Arthropathy; Magnetic resonance imaging.

\section{INTRODUÇÃO}

Metatarsalgia refere-se a dor na região do pé que contém os cinco metatarsais, podendo estar relacionada a lesões de partes moles, ósseas, articulares e periarticulares ${ }^{(\mathbf{1 , 2})}$. As manifestações clínicas nos pacientes com metatarsalgia podem ser inespecíficas ou atípicas e com avaliação limitada pela radiologia convencional, sendo indicado o prosseguimento do estudo com a ressonância magnética $(\mathrm{RM})^{(\mathbf{3})}$, por meio da qual é possível, na maioria dos casos, definir a localização anatômica, a extensão da lesão e o envolvimento de estruturas adjacentes, possibilitando um diagnóstico mais preciso, além de permitir a detecção de lesões ocultas associadas que podem alterar o prognóstico.

\footnotetext{
* Trabalho realizado no Diagnósticos da América (Delboni/ Lavoisier), São Paulo, SP.

1. Médicos Radiologistas do Diagnósticos da América.

2. Chefe do Setor de Músculo-esquelético do Serviço de Diagnóstico por Imagem do Hospital Santa Casa de Misericórdia de São Paulo, Médica Radiologista do Diagnósticos da América.

3. Médicos Colaboradores do Departamento de Diagnóstico por Imagem da Universidade Federal de São Paulo-Escola Paulista de Medicina, Médicos Radiologistas do Diagnósticos da América.

4. Professor Adjunto Doutor do Departamento de Diagnóstico por Imagem da Universidade Federal de São Paulo-Escola Paulista de Medicina, Médico Radiologista do Diagnósticos da Amé rica.

Endereço para correspondência: Dra. Maria Carolina Guimarães. Rua Antonio José Gonçalves, 105, ap. 62. São Paulo, SP, 04152-140. E-mail: thiagust@ig.com.br

Recebido para publicação em 28/10/2004. Aceito, após revisão, em 29/8/2005.
}

Nosso objetivo é descrever e ilustrar, em ensaio iconográfico com imagens de RM, as principais doenças que causam metatarsalgia. Para desenvolver este ensaio, optamos por dividir as causas de metatarsalgia em tumorações de partes moles, lesões traumáticas, infração de Freiberg, doenças dos sesamóides, doenças articulares e pé diabético, a fim de facilitar o diagnóstico diferencial das lesões.

\section{TUMORAÇÕES NÃO NEOPLÁSICAS DE PARTES MOLES}

Amplo espectro de tumorações de partes moles ocorre no pé e tornozelo, a maioria delas benigna, sendo as não neoplásicas, como o neuroma de Morton, o ganglion e a fibromatose plantar, muito mais freqüentes do que as neoplasias verdadeiras ${ }^{(\mathbf{4})}$.

\section{Neuroma de Morton $\times$ bursite}

As afecções que acometem o espaço entre as cabeças dos metatarsais são em pequeno número, representadas basicamente pelo neuroma de Morton e pelas bursites.

O neuroma interdigital, ou de Morton, é causa comum de metatarsalgia. É uma lesão não neoplásica que consiste de fibrose perineural e degeneração nervosa ${ }^{(3)}$. Por definição, é centrado na região da banda neurovascular, entre as cabeças dos metatarsais (mais freqüentemente entre o terceiro e o quarto raios) e abaixo do ligamento metatarsal transverso profundo ${ }^{(5)}$. Pode estar presente em pacientes assintomáticos ${ }^{(6)} \mathrm{e}$ alguns trabalhos propõem que, para ser considerado relevante na RM, o neuroma deve ter diâmetro transverso mínimo de 5 mm, além de estar associado a achados clínicos compatíveis ${ }^{(5,7)}$. O aspecto típico é de lesão com sinal baixo ou intermediário em T1 e baixo em T2 (representando o componente fibroso da lesão) e, geralmente, com realce moderado e homogêneo, mais bem identificado nas sequiências T1 com supressão de gordura (Figura 1$)^{(\mathbf{8})}$. O uso de gadolínio é controverso $^{(\mathbf{9 , 1 0})}$, porém auxilia na diferenciação entre as tumorações sólidas e císticas, como as bursites, que freqüentemente acompanham essas lesões intermetatarsais $^{(\mathbf{8})}$.

As bursites também podem estar presentes em casos de trauma, infecção, artrite reumatóide, gota. Além de acometerem as bursas intermetatarsais (Figura 2) podem ocorrer nas bursas adventícias (localizadas abaixo das cabeças dos metatarsais) (Figura 3). São caracterizadas na RM como coleções líquidas bem definidas, com hipossinal em T1 e hipersinal em T2/STIR e com realce periférico após a administração do meio de contraste ${ }^{(3)}$. Pequenas coleções com diâmetro transverso de $3 \mathrm{~mm}$ ou menos nas três primeiras bursas intermetatarsais podem ser fisiológicas ${ }^{(7)}$. 


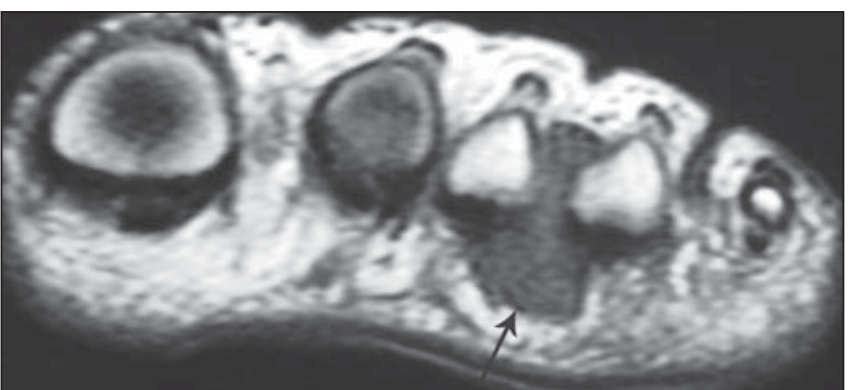

A

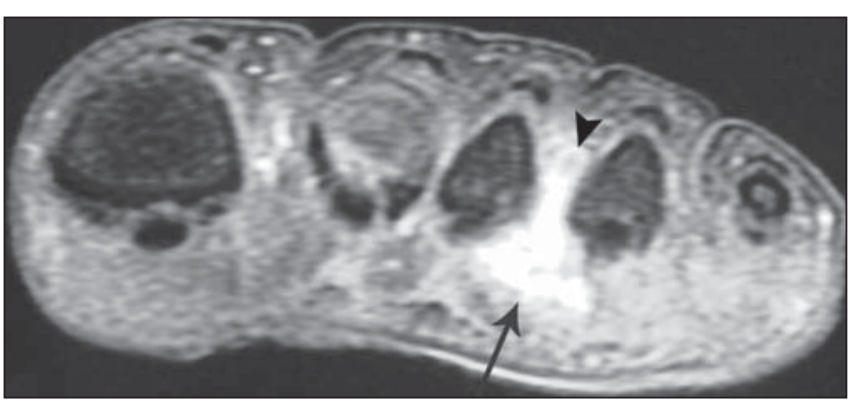

C

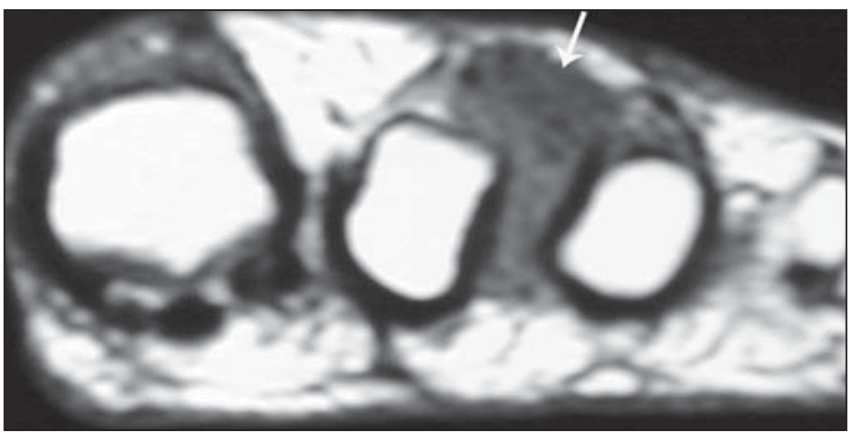

A

Figura 2. Bursite intermetatarsal. Coronal T1 (A) e coronal T1 pós-contraste com supressão de gordura (B) - formação hipointensa, bem delimitada, entre as cabeças dos segundo e terceiro metatarsais, com realce periférico pelo meio de contraste (setas).

\section{Ganglion}

Os ganglions são lesões císticas com conteúdo mucinoso e cápsula fibrosa. No pé, com frequiência, localizam-se na região dorsal, adjacente a cápsula articular, bainha tendínea, tendão ou ligamento e, usualmente, não há comunicação demonstrável com o espaço articular. As lesões apresentam-se bem delimitadas, comumente de aspecto lobulado, com septações e com hipossinal ou sinal intermediário em T1 e hipersinal em $\mathrm{T} 2$ e fino realce periférico pelo meio de contraste (Figura 4) ${ }^{(\mathbf{4 , 6})}$.

\section{Fibromatose plantar}

A fibromatose plantar consiste de proliferação fibrosa que, em geral, ocorre no aspecto medial e superficial da fáscia plan-

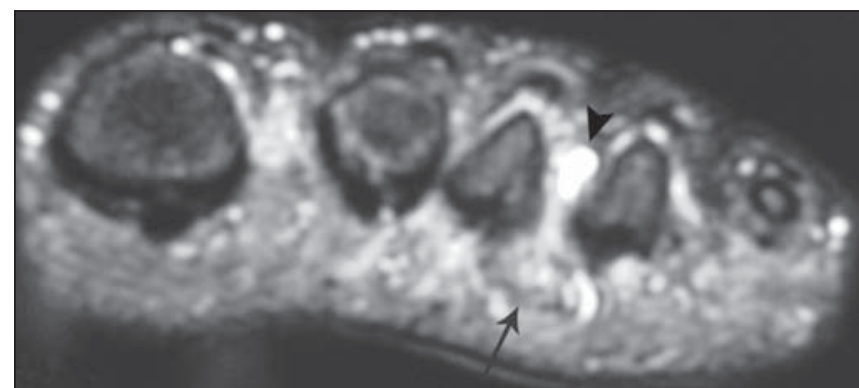

B

Figura 1. Neuroma de Morton. A: Coronal T1 - formação nodular, hipointensa, bem delimitada, entre as cabeças do terceiro e quarto metatarsais (seta). B: Coronal T2 com supressão de gordura - a lesão apresenta hipossinal heterogêneo (seta) e há líquido na bursa intermetatarsal (cabeça de seta). c: Coronal T1 pós-contraste com supressão de gordura - realce intenso e homogêneo do nódulo (seta) e periférico da bursa (cabeça de seta).

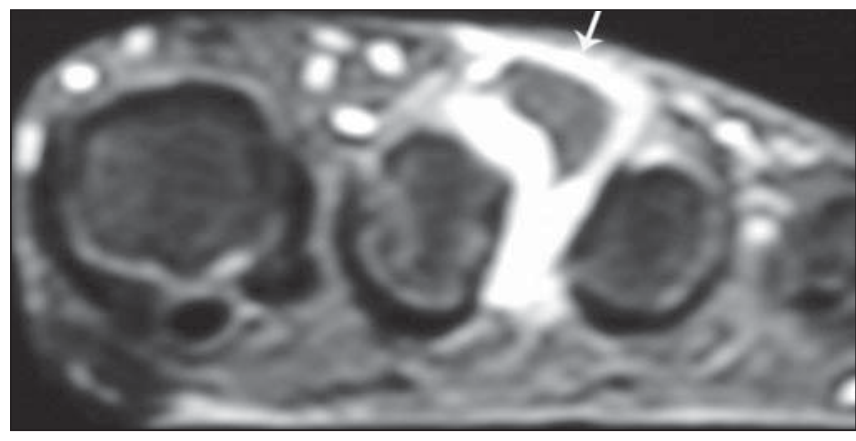

B $\operatorname{tar}^{(3)}$. Um ou mais nódulos podem estar presentes, caracterizados por hipossinal ou sinal intermediário em T1 e, na maioria dos casos, hipossinal em T2 (Figura 5). Geralmente, não há edema inflamatório adjacente. O realce pelo meio de contraste é variável $^{(3,11)}$.

\section{LESÕES TRAUMÁTICAS}

\section{Ruptura da placa plantar}

A placa plantar é uma estrutura fibrocartilaginosa que reforça a cápsula articular das metatarsofalângicas. É identificada nas imagens de RM ponderadas em T1 e T2 como uma banda regular com hipossinal, localizada junto ao aspecto plantar da cabeça do metatarsal e que se insere na base da falange proximal, adjacente à superfície articular, profundamente aos tendões flexores. As rupturas da placa plantar podem estar relacionadas a eventos traumáticos agudos ou traumas repetitivos subagudos (lesões degenerativas) $^{(\mathbf{5})}$.

Lesões traumáticas agudas, em geral, são causadas por hiperextensão, principalmente da primeira metatarsofalângica, resultando em ruptura completa ou parcial da placa plantar, que se caracteriza na RM por descontinuidade e hipersinal dessa estrutura, comumente acompanhada de edema de partes moles e de lesões condrais e subcondrais (Figura 6) ${ }^{(\mathbf{3})}$. Lesões degenerativas tendem a ocorrer da segunda à quinta metatarsofalângicas, mais comumente na segunda metatarsofalângica e em mulheres 


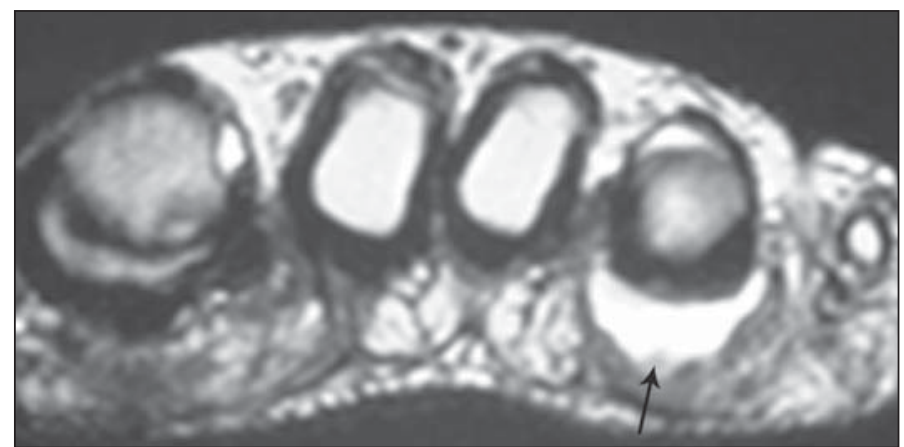

Figura 3. Bursite adventícia. Coronal T2 - coleção líquida abaixo da cabeça do quarto metatarsal (seta). que utilizam sapato de salto alto e bico fino. Achados de RM incluem aumento do sinal e descontinuidade da placa plantar em T2/ STIR, podendo estar associados a tenossinovite do flexor, sinovite da articulação metatarsofalângica e hiperextensão da falange proximal ${ }^{(12)}$.

\section{Lesões ligamentares}

Achados de RM de lesões agudas do ligamento colateral (Figura 7) incluem descontinuidade, desinserção e espessamento
Figura 4. Ganglion. A: Sagital T1 - formação cística, bem delimitada, com hipossinal, de localização periarticular na face dorsal do pé (seta). B: Sagital STIR - a lesão apresenta hipersinal e contornos lobulados (seta).

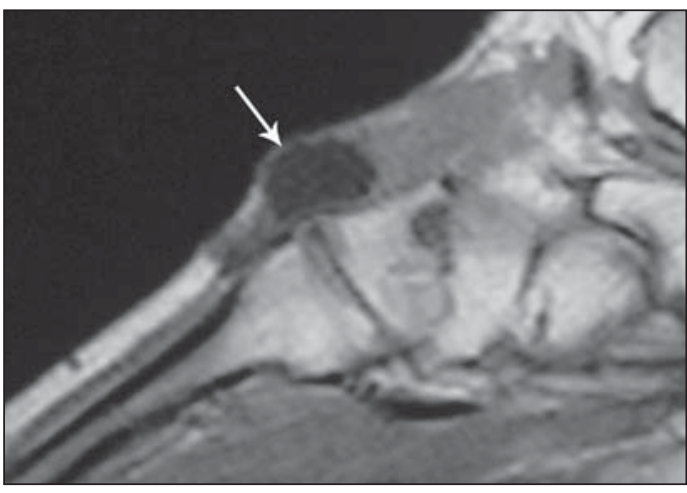

A

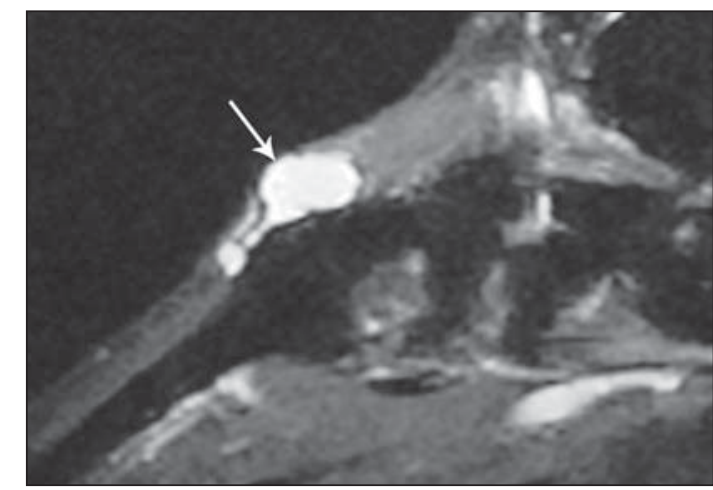

B

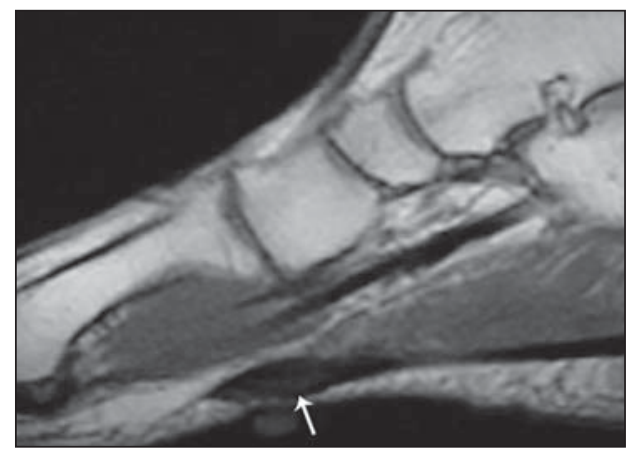

A

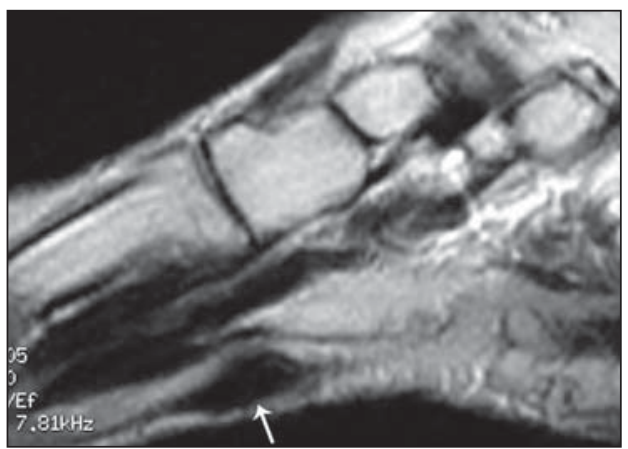

B

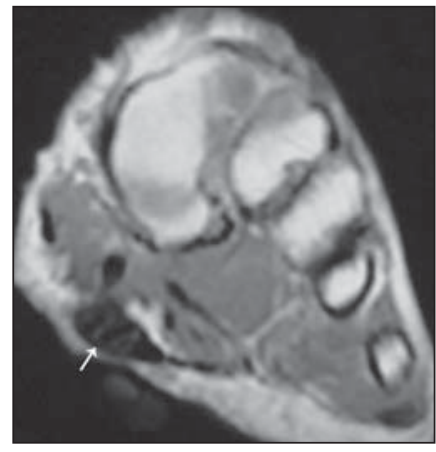

C

Figura 5. Fibromatose plantar. A: Sagital T1 - espessamento nodular focal da fáscia plantar, caracterizado por sinal baixo/intermediário (seta). B: Sagital T2 - a lesão apresenta hipossinal (seta). C: Coronal T1 pós-contraste - o espessamento é localizado na região medial da fáscia e há tênue realce pelo meio de contraste (seta).

Figura 6. Lesão traumática aguda da placa plantar da segunda metacarpofalângica. A: Radiografia simples - hiperextensão da segunda falange proximal (seta). B: Sagital STIR edema medular subcondral na cabeça do metatarsal (asterisco) e hipersinal na topografia da inserção da placa plantar (seta).

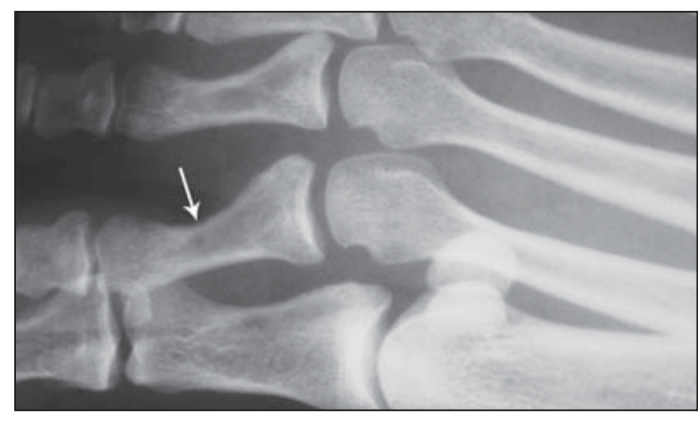

A

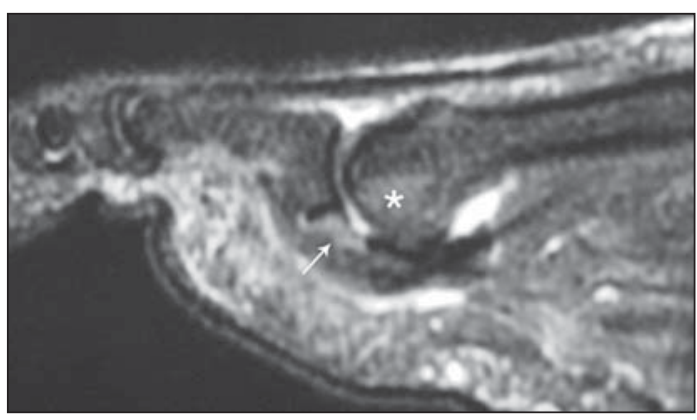

B 


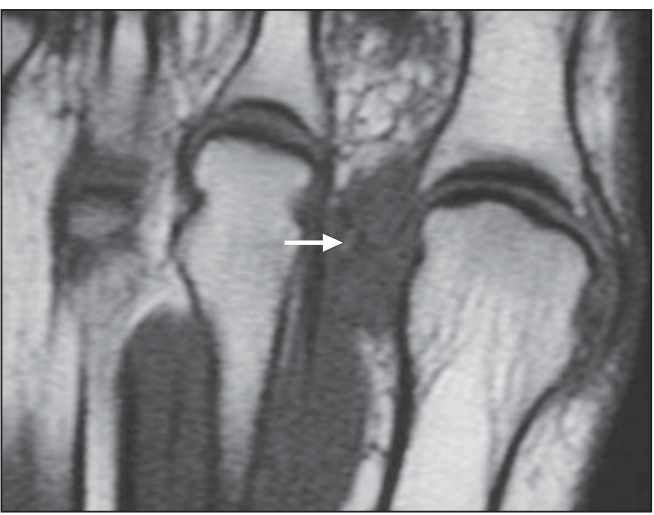

A

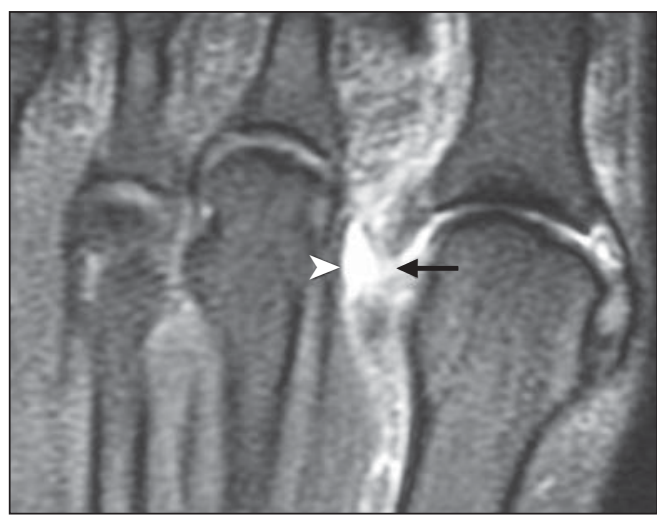

B

Figura 7. Lesão traumática aguda do ligamento colateral lateral da primeira metacarpofalângica. A: Axial T1 - indefinição do ligamento e obliteração dos planos gordurosos adjacentes (seta). B: Axial STIR - espessamento e descontinuidade do ligamento (seta), edema periligamentar e extravasamento do líquido intra-articular (cabeça de seta).

do ligamento, associados a aumento do sinal intraligamentar (edema/hemorragia). Obliteração de planos gordurosos adjacentes e extravasamento de líquido para partes moles também podem ser observados ${ }^{(\mathbf{1 3})}$.

\section{Fraturas de estresse}

Fraturas de estresse dos metatarsais são comuns em corredores, bailarinas, recrutas militares e esportistas. Condições que resultam em alteração da biomecânica, incluindo redução da altura do arco plantar, hálux valgo e cirurgia recente do hálux, podem aumentar o risco de desenvolver fratura de estresse ${ }^{(3)}$. As regiões diafisárias médias e distais do segundo ao quarto metatarsais são mais freqüentemente envolvidas. A fratura é caracterizada como uma imagem linear de baixo sinal contígua à cortical, mais bem individualizada em T2/
STIR, associada a edema medular. Freqüentemente, há espessamento cortical e edema de partes moles adjacentes associados (Figura 8) $)^{(\mathbf{5})}$.

\section{INFRAÇÃO DE FREIBERG}

Infração de Freiberg é uma lesão que ocorre na cabeça dos metatarsais (usualmente a segunda ou terceira) e é caracterizada por colapso do osso subcondral, osteonecrose e fissuras condrais. Caracteriza-se, na RM, como área bem delimitada de hipossinal na cabeça do metatarsal, com aumento do sinal em T2/STIR nas fases agudas, progredindo para colapso do osso subcondral, com achatamento da superfície articular, irregularidade da epífise e redução do sinal da medula óssea nas seqüências ponderadas em T2 (esclerose óssea)
(Figura 9). Num estágio mais tardio, ocorrem redução do espaço articular e osteofitose marginal ${ }^{(3)}$.

\section{DOENÇAS DOS SESAMÓIDES}

As principais afecções que ocorrem nos sesamóides são a osteoartrose, a sesamoidite, as lesões por estresse e a osteonecrose. O diagnóstico diferencial entre as três últimas pode ser difícil numa fase inicial.

A sesamoidite é uma condição inflamatória decorrente de traumas repetitivos no aspecto plantar do antepé. Os achados de RM incluem aumento do sinal da medula óssea em T2/STIR, com sinal normal ou reduzido em T1 (Figura 10). As alterações de sinal da medula óssea são semelhantes às das lesões por estresse e pode haver sobreposição entre essas condições ${ }^{(14)}$.

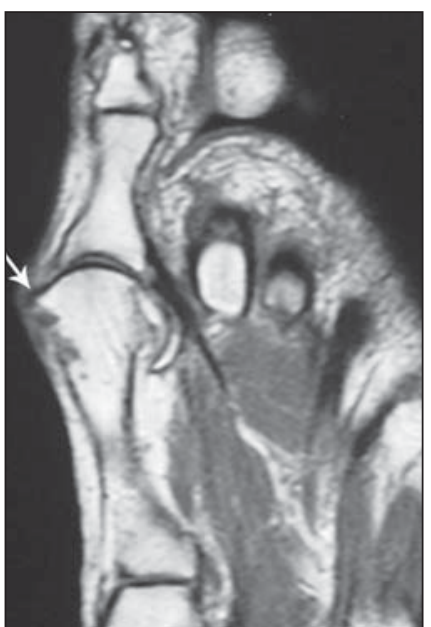

A

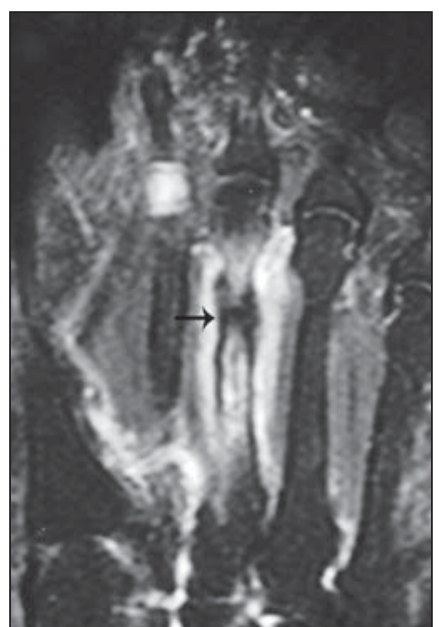

B

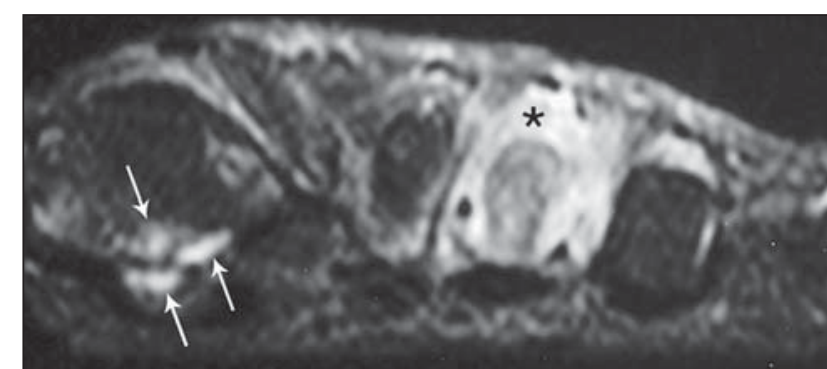

C

Figura 8. Osteoartrose da primeira metacarpofalângica e fratura de estresse da diáfise do terceiro metatarsal. A: Axial T1 - hálux valgo, osteófito marginal na cabeça do primeiro metatarsal (seta). B: Axial STIR - linha de hipossinal representando o traço de fratura (seta), associada a espessamento cortical e edema medular e de partes moles adjacentes. C: Coronal STIR - edema envolvendo parcialmente a medular da porção dorsal dos sesamóides e da cabeça do primeiro metatarsal adjacente, com aspecto em "beijo" (setas). Edema medular e de partes moles do terceiro metatarsal (asterisco). 


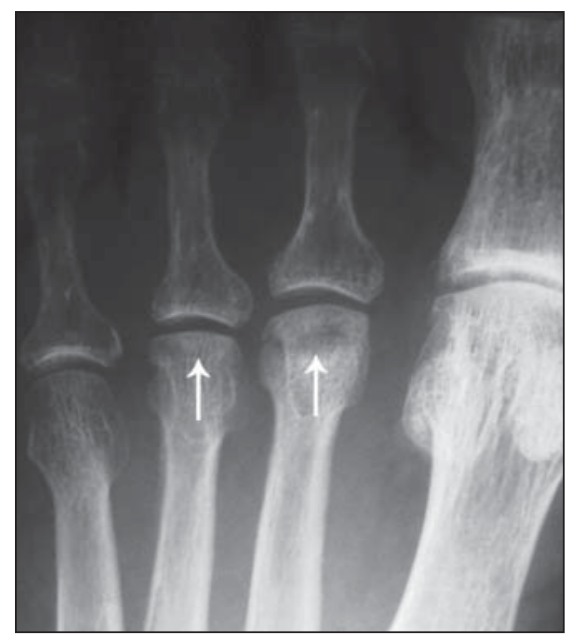

A

Figura 9. Infração de Freiberg. A: Radiografia simples - achatamento e fraturas subcondrais das cabeças dos segundo e terceiro metatarsais (setas). B: Axia T1 - hipossinal na região subcondral (setas) e nas diáfises desses metatarsais. C: Axial STIR - focos de hipossinal caracterizando esclerose subcondral na cabeça desses metatarsais (setas) e edema medular das diáfises correspondentes.

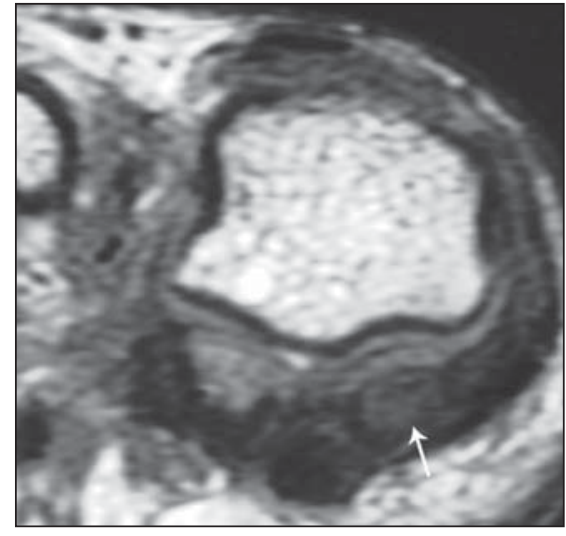

A

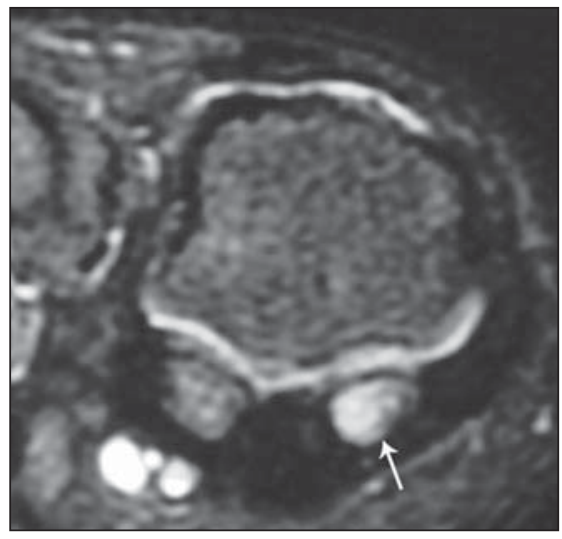

B

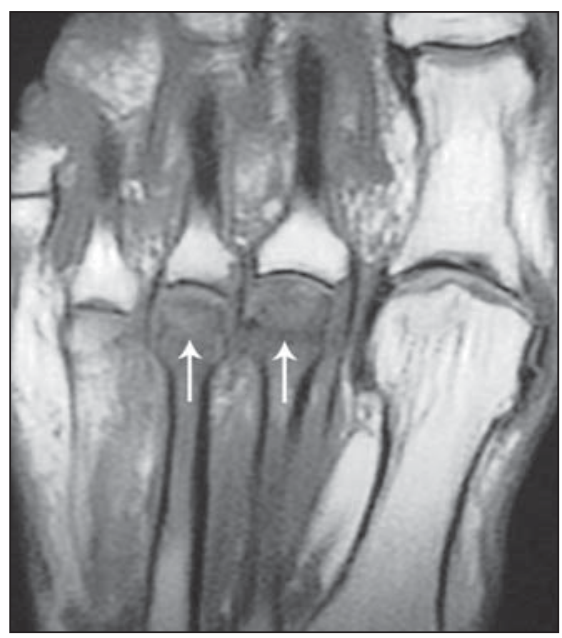

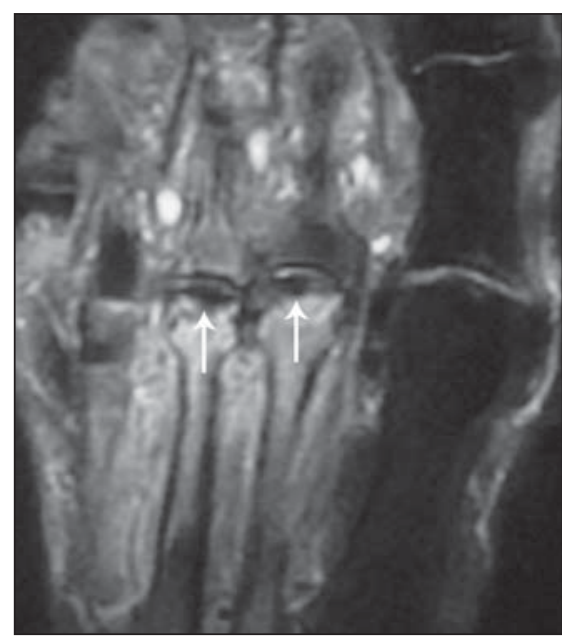

C

Figura 10. Sesamoidite. A: Coronal T1 - hipossinal do sesamóide medial (seta). B: Coronal STIR - hipersinal da medular óssea (seta). C: Coronal T1 póscontraste com supressão de gordura - realce homogêneo (seta).

Lesões por estresse acometem principalmente o sesamóide medial, que é maior e suporta maior carga, e também podem ocorrer na sincondrose entre as porções de um sesamóide bipartido ${ }^{(14)}$. As fraturas dos sesamóides usualmente são transversas e com margens irregulares, e são identificadas como uma imagem linear de hipossinal com edema medular associado (Figura 11); edema de partes moles adjacentes pode ser encontrado ${ }^{(11)}$.

A osteonecrose ocorre mais freqüentemente no sesamóide lateral. $\mathrm{O}$ achado inicial de RM pode ser de edema medular, semelhante ao encontrado na sesamoidite e nas lesões por estresse. O realce pode ser bastante variável. Num estágio mais avançado da osteonecrose, caracterizado por irregularidade cortical, colapso ósseo e formação de cistos (Figura 12), o diagnóstico é fácil. A diferenciação com osteoartrose se dá pela presença das lesões "em beijo" entre a cabeça do metatarsal e o sesamóide e pelas alterações articulares adjacentes (Figura 8$)^{(14)}$.

\section{DOENÇAS ARTICULARES}

\section{Osteoartrose}

É comum na primeira metatarsofalângica, podendo envolver os sesamóides (Figura 8). Hálux valgo pode ser um fator precipitante do processo degenerativo. Os achados de RM na osteoartrose incluem redução do espaço articular, osteófitos marginais, cistos subcondrais (com aspecto em

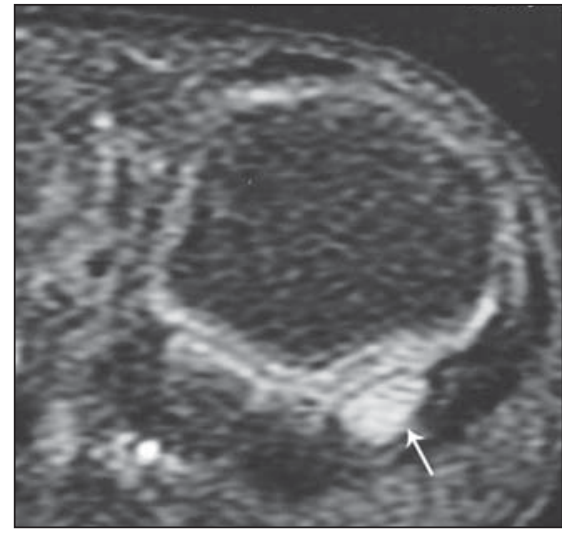

C "beijo" nas superfícies ósseas adjacentes), edema medular subcondral e esclerose subcondral $^{(3)}$.

\section{Artrite reumatóide}

A artrite reumatóide comumente afeta os pés, nos quais as lesões mais precoces ocorrem nas metatarsofalângicas ${ }^{(3)}$. A RM deve ser o método de imagem de escolha na suspeita de artrite reumatóide, pois possibilita o seu diagnóstico em fases iniciais, pela detecção de sinovite e edema medu$\operatorname{lar}^{(15,16)}$. Também são encontrados no curso da artrite reumatóide erosões marginais, pannus sinovial (Figura 13), derrame articular, afilamento da cartilagem articular e cistos subcondrais, além de bursite e tenossinovite. O pannus apresenta hipossinal ou 


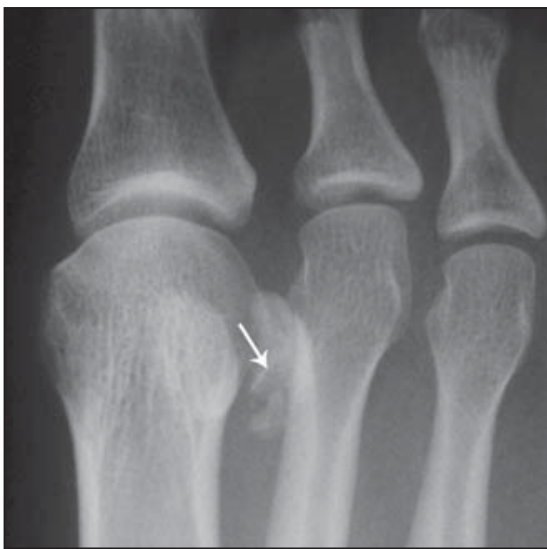

A

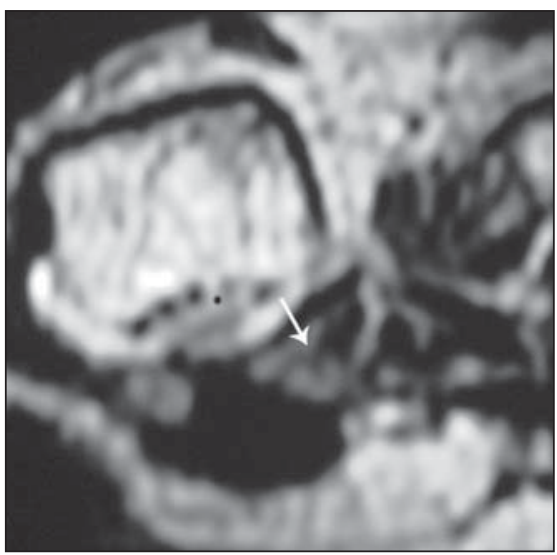

B

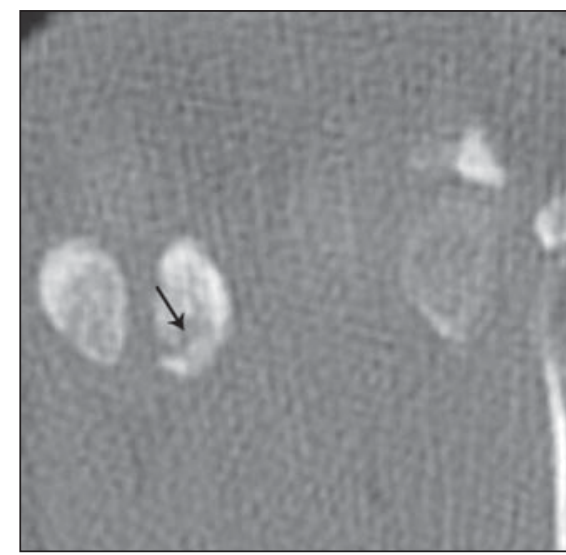

C

Figura 11. Fratura de estresse do sesamóide lateral. A: Radiografia simples - fratura oblíqua (seta). B: Coronal T2 - traço de hipossinal, caracterizando fratura (seta). C: TC axial - traço de fratura (seta) com extensão até a cortical medial.

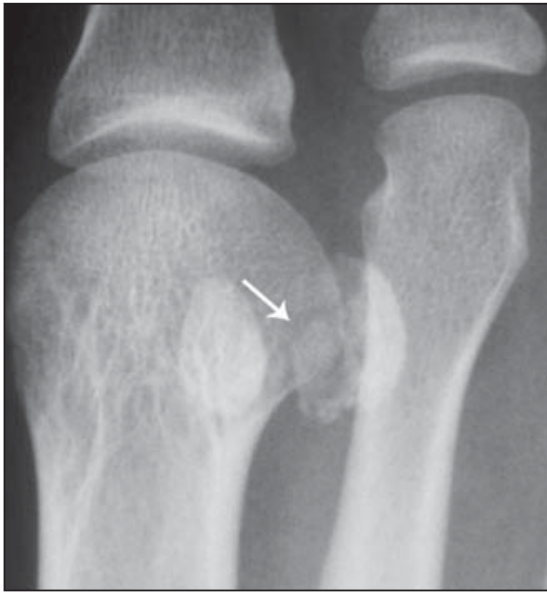

A

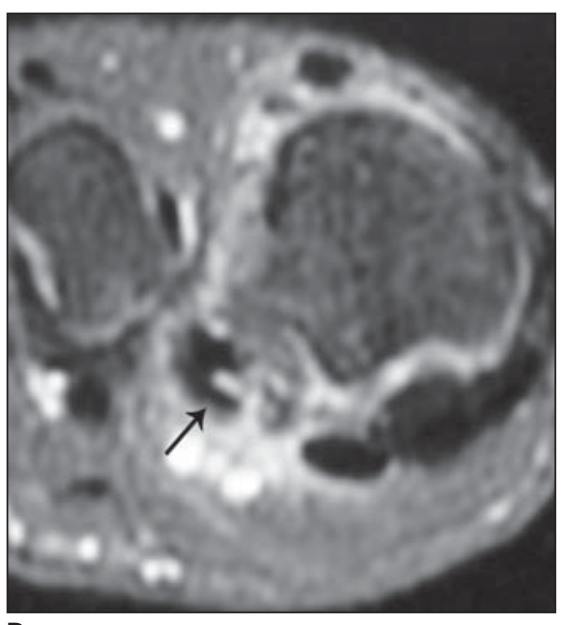

D

sinal intermediário em T1 e hipersinal em $\mathrm{T} 2$ com realce homogêneo pelo meio de contraste (hipervascular), e na fase crônica pode mostrar hipossinal em T2, decorrente de fibrose e deposição de hemossiderina ${ }^{(3)}$.

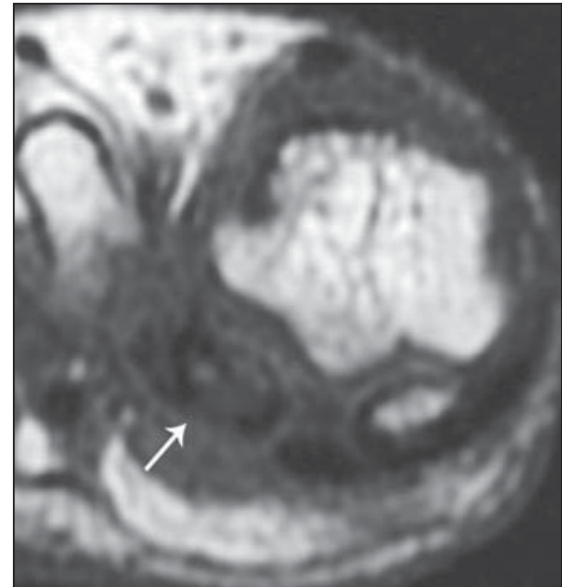

B

Figura 12. Osteonecrose do sesamóide lateral. A: Radiografia simples - esclerose e fragmentação do sesamóide (seta). B: Coronal T1 - hipossinal do sesamóide lateral (seta). C: Coronal STIR - hipersinal da medular deste sesamóide (seta). D: Coronal T1 pós-contraste com supressão de gordura: realce heterogêneo do sesamóide, persistindo áreas hipointensas (seta).

\section{Gota}

A gota afeta mais freqüentemente a primeira metatarsofalângica. Os achados na fase aguda são inespecíficos e incluem derrame articular e espessamento sinovial.

Os tofos (Figura 14) aparecem na fase crônica da doença, podem produzir erosões ósseas, ter localização intra-articular ou periarticular ou manifestar-se como lesão de partes moles. Apresentam-se com sinal baixo ou intermediário em T1 e variável em $\mathrm{T} 2$, mas geralmente com focos de hipossinal que sugerem o diagnóstico. Edema medular pode ocorrer adjacente ao tofo intraósseo $^{(3,5)}$.

\section{PÉ DIABÉTICO: OSTEOMIELITE $\times$ NEUROARTROPATIA}

A osteomielite é uma complicação comum em pacientes diabéticos e, em geral, é decorrente da contaminação através de uma lesão de partes moles. Os locais mais comuns de infecção de partes moles e osteomielite secundária são áreas onde se localizam pontos de maior pressão, como abaixo das cabeças dos metatarsais e do calcâneo, áreas em que pode haver úlceras cutâneas. Os achados de RM incluem hipossinal em T1 e hipersinal em T2/STIR da medula óssea, com realce pelo meio de contraste. A presença de úlcera cutânea, 


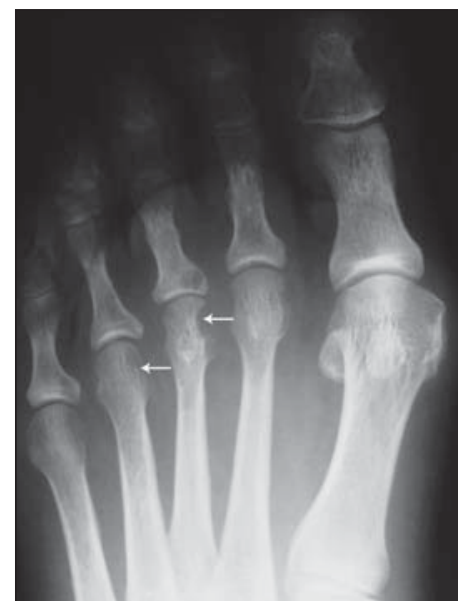

A

Figura 13. Artrite reumatóide. A: Radiografia simples - erosões marginais nas cabeças dos segundo e terceiro metatarsais (setas). B: Axial STIR - edema medular nos metatarsais e falanges proximais dos segundo e terceiro raios, erosões marginais nas cabeças dos metatarsais (setas). Coronal T1 (C) e coronal T1 pós-contraste (D) - espessamento sinovial com realce pelo meio de contraste (asterisco).

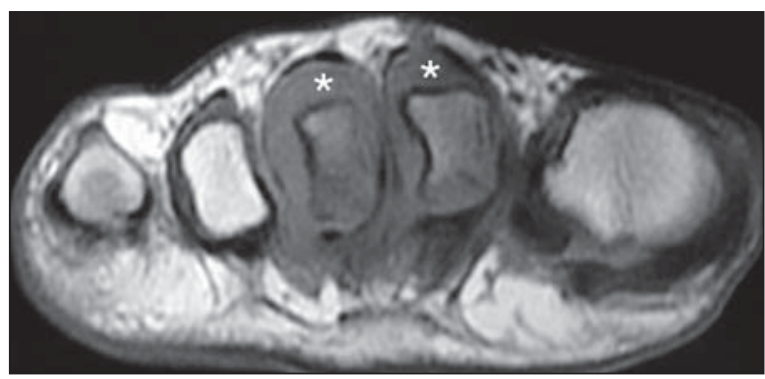

C

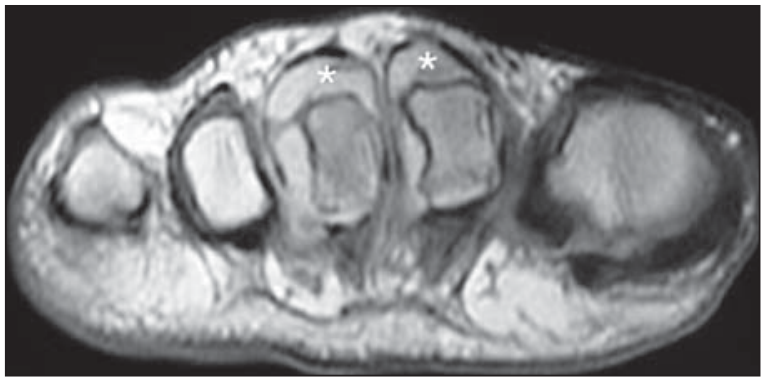

D

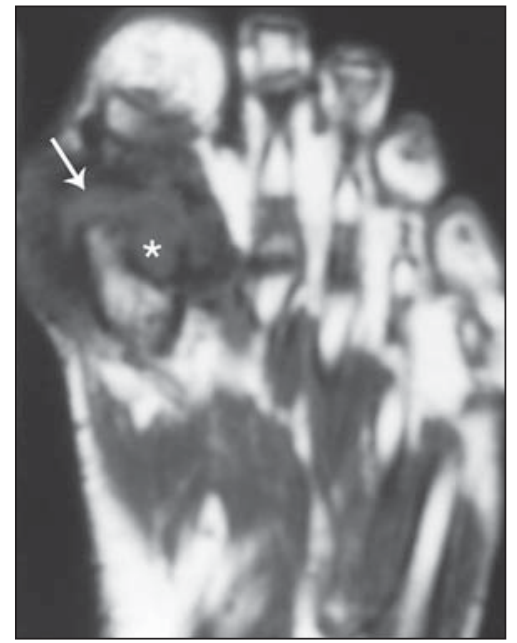

A

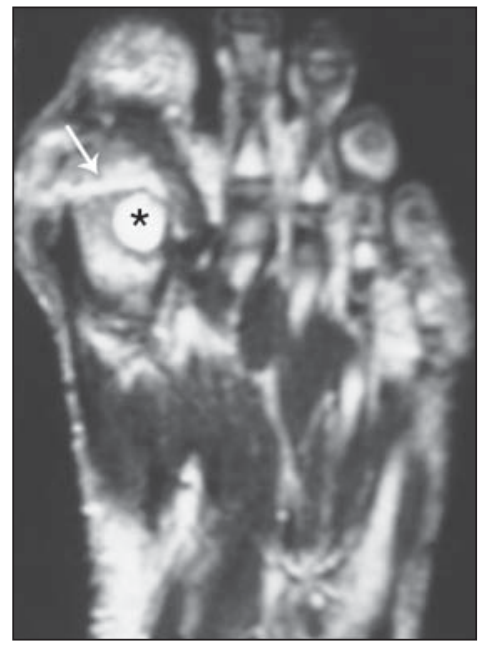

B

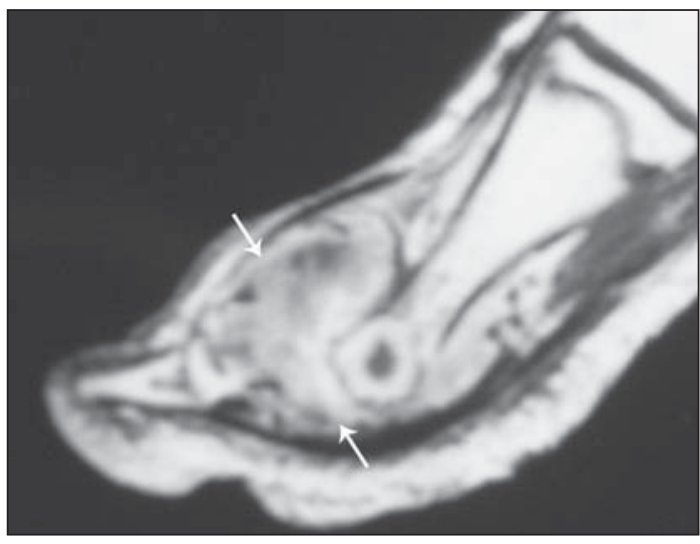

C

Figura 14. Gota. A: Axial T1 - formação com hipossinal — tofo (seta) - envolvendo a primeira metacarpofalângica, com erosão óssea (asterisco) associada. B: Axial T2 - a lesão apresenta hipersinal (seta) e erosão óssea (asterisco). C: Sagital T1 pós-contraste - realce da lesão (setas).

Figura 15. Osteomielite e abscesso em paciente diabético. Sagital T2 (A) e sagital T1 póscontraste com supressão de gordura (B) - coleção líquida com realce periférico envolvendo metatarsal previamente amputado e que apresenta espessamento cortical e edema medular. Focos de hipossinal em todas as seqüências, compatíveis com gás (setas).

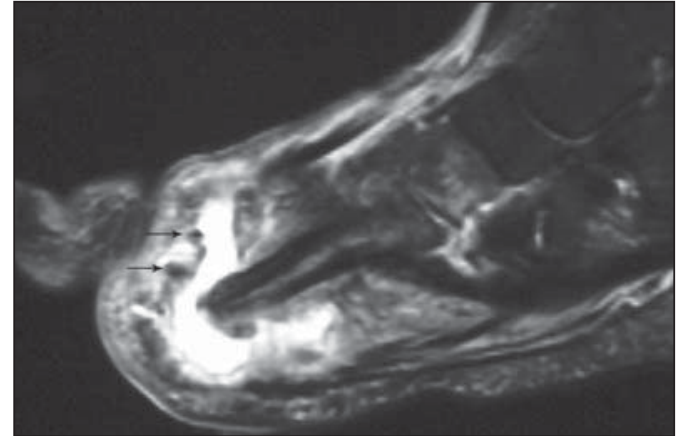

A

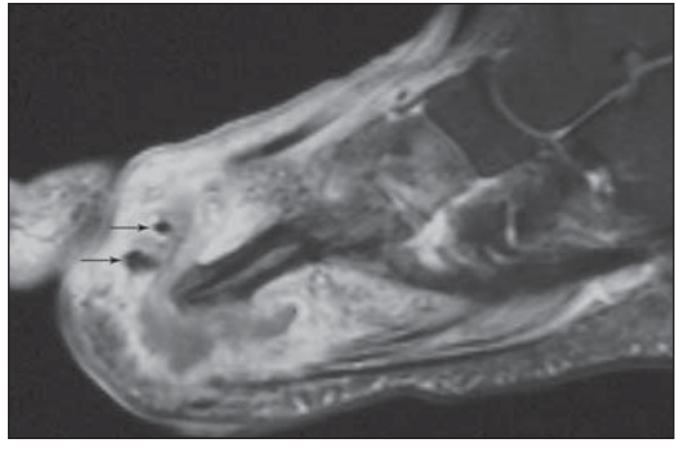

B 
celulite, abscesso, trajeto fistuloso, descontinuidade da cortical e a evidência de gás favorecem a possibilidade de osteomielite (Figura 15). As características de RM da fase aguda da neuroartropatia são semelhantes às da osteomielite, com a medula óssea apresentando sinais de edema (Figura 16). Porém, a localização da lesão óssea no médio-pé, mantendo alguma distância da infecção de partes moles, o envolvimento poliarticular e a ausência de lesões corticais localizadas favorecem o diagnóstico de neuroartropatia. Achados na neuroartropatia crônica incluem esclerose óssea (hipossinal subcondral em T1 e T2), cistos periarticulares, fragmentação óssea, luxações e subluxações, derrame articular e edema de partes moles ${ }^{(\mathbf{1 7}, 18)}$.

\section{CONCLUSÃO}

$\mathrm{Na}$ avaliação das metatarsalgias, os achados de RM associados a dados da história clínica e do exame físico podem contribuir de forma decisiva para estabelecer o diagnóstico e/ou estadiar a lesão. O uso combinado com outros métodos de imagem, como a radiografia simples, a tomografia computadorizada e a ultra-sonografia, pode, freqüentemente, acrescentar informações relevantes para estabelecer o diagnóstico e a conduta.

\section{REFERÊNCIAS}

1. Quirk R. Metatarsalgia. Aust Fam Physician 1996; 25:863-869.

2. Wu KK. Morton neuroma and metatarsalgia. Cur Opin Rheumatol 2000;12:131-142.

3. Ashman CJ, Klecker RJ, Yu JS. Forefoot pain involving the metatarsal region: differential diagnosis with MR imaging. RadioGraphics 2001;21: 1425-1440.

4. Foo LF, Raby N. Tumours and tumour-like lesions in the foot and ankle. Clin Radiol 2005;60:308332.

5. Yu JS, Tanner JR. Considerations in metatarsalgia

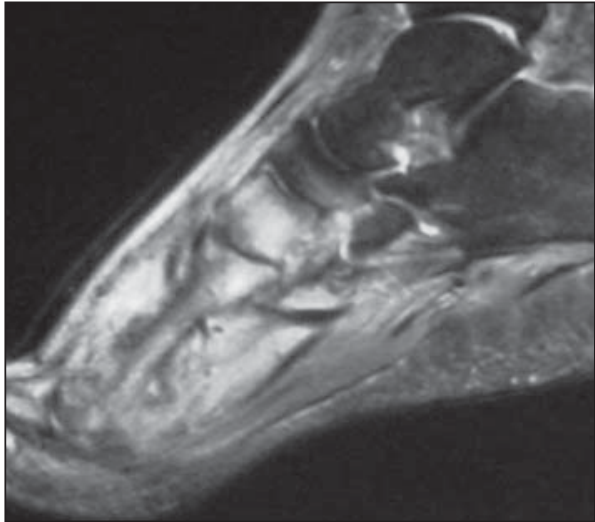

A

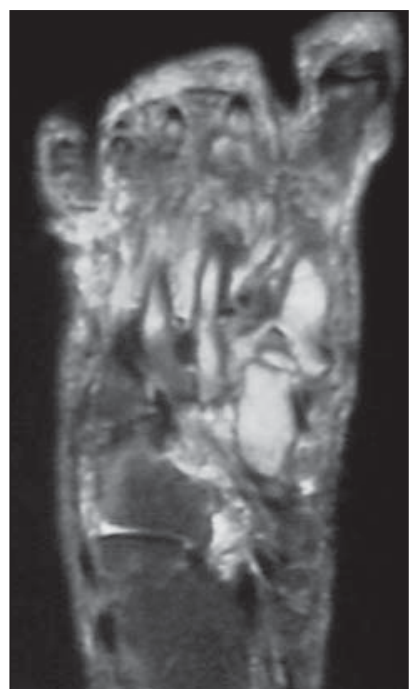

B

Figura 16. Neuroartropatia diabética. Sagital STIR (A) e axial STIR (B) - edema de partes moles e da medular dos ossos do médio-pé e metatarsais, sem evidências de abscessos, úlceras ou lesões corticais definidas.

and midfoot pain: an MR imaging perspective. Semin Musculoskelet Radiol 2002;6:91-104.

6. Llauger J, Palmer J, Monill JM, Franquet T, Bagué S, Rosón N. MR imaging of benign soft-tissue masses of the foot and ankle. RadioGraphics 1998;18:1481-1498.

7. Zanetti M, Strehle JK, Zolinger H, Hodler J. Morton neuroma and fluid in the intermetatarsal bursae on MR images of 70 asymptomatic volunteers. Radiology 1997;203:516-520.

8. Gentili A, Sorenson S, Masih S. MR imaging of soft-tissue masses of the foot. Semin Musculoskelet Radiol 2002;6:141-152.

9. Zanetti M, Ledermann T, Zollinger H, Hodler J. Efficacy of MR imaging in patients suspected of having Morton's neuroma. AJR Am J Roentgenol 1997; 168:529-532.

10. Williams JW, Meaney J, Whitehouse GH, Klenerman L, Hussein Z. MRI in the investigation of Morton's neuroma: which sequences? Clin Radiol 1997;52:46-49.

11. Stoller DW, Ferkel RD. The ankle and foot. In: Stoller DW, editor. Magnetic resonance imaging in orthopaedics \& sports medicine. Philadelphia: Lippincott-Raven, 1997;443-595.

12. Yao L, Do HM, Cracchiolo A, Farahani K. Plantar plate of the foot: findings on conventional ar- thrography and MR imaging. AJR 1994;163: 641-644.

13. Clavero JA, Alomar X, Monill JM, et al. MR imaging of ligament and tendon injuries of the fingers. RadioGraphics 2002;22:237-256.

14. Karasick D, Schweitzer ME. Disorders of the hallux sesamoid complex: MR features. Skeletal Radiol 1998;27:411-418.

15. Ostendorf B, Scherer A, Mödder U, Schneider M Diagnostic value of magnetic resonance imaging of the forefeet in early rheumatoid arthritis when findings on imaging of the metacarpophalangeal joints of the hands remain normal. Arthritis Rheum 2004;50:2094-2102.

16. Sommer OJ, Kladosek A, Weiler V, Czembirek H, Boeck M, Stiskal M. Rheumatoid arthritis: a practical guide to state-of-the-art imaging, image interpretation, and clinical implications. RadioGraphics 2005;25:381-398.

17. Marcus CD, Ladam-Marcus VJ, Leone J, Malgrange D, Bonnet-Gausserand FM, Menanteau BP. MR imaging of osteomyelitis and neuropathic osteoarthropathy in the feet of diabetics. RadioGraphics 1996;16:1337-1348.

18. Gil HC, Morrison WB. MR imaging of diabetic foot infection. Semin Musculoskelet Radiol 2004; 8:189-198. 